\title{
ADULT EDUCATION IN MOZAMBIQUE: BETWEEN EXPECTATIONS AND POSSIBILITIES
}

\author{
Alzira A. M. Manuel, Domingos Buque, Rosário Quive \\ Eduardo Mondlane University, Mozambique \\ E-mail: alzira@uem.mz; alziramanuel92@gmail.com, domingos. \\ buque@uem.mz,rosquive@yahoo.com.br
}

\begin{abstract}
Adult education has been and continues being an important area of education. In developing contexts, it is considered the way for social inclusion and poverty reduction and it is expected to provide knowledge, skills and values to youth and adults who did not get opportunity to education in their early age. Adult education also serves as a way to improve people's competences throughout their life span. However, the concept of adult education in Mozambique has been used as literacy, referring only to the development of reading, writing and calculation skills. Using content analysis of documents, this research attempts to gain insight of adult education in the context of Mozambique. The findings reveal that adult education in the perspective of change and development as it is in Mozambique is linked to the objectives of poverty reduction and social inclusion. In this sense quality and relevance in adult education, as in other type of education, is needed to be able to develop functional knowledge and skills to youth and adults and allow them continuing learning in their life. Literacy and adult education have been considered an important field for social and economic development in the country, but contextual factors contribute to a narrow perspective of adult education, focusing mainly on literacy and numeracy as its final goal.

Keywords: adult education, poverty reduction, social inclusion.
\end{abstract}

\section{Introduction}

The context of social and economic changes caused by globalization and the neoliberal policies increases social disintegration, exclusion and poverty, particularly in developing societies. Education, including adult education, is seen as one of the ways to enhance people's competences to help them to cope more effectively with the challenges of changes and their increased participation in society.

Adult education is considered to be one of the ways that can help many adults and out of school youth to develop knowledge and skills as a continuing process. This vision is important not only to help those who did not get opportunity to education in their early age or those who dropped out prematurely from school, but also to allow people to learn throughout their life time. However, adult education in the context of Mozambique is implemented in a restricted way, focusing on literacy and numeracy teaching. This approach limits the youth and adults' opportunities for the acquisition of functional skills. This means that adult education should be seen beyond literacy, as literacy skills are the foundations for the development of further skills and competences. Thus, literacy cannot be the ultimate goal of adult education.

Adult education is a multifaceted and complex field of education; reducing it to literacy only is to hinder the educational process (Gadotti, 2009). In this sense, the aim of this research is to get insight of adult education in Mozambique, reflecting between its goals and practices. For this purpose, the following research questions were formulated: 


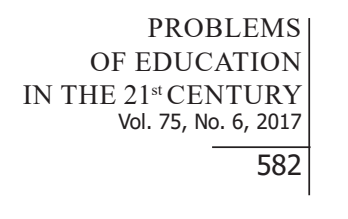

PROBLEMS

DUCATION

$21^{\text {st }}$ CENTURY

582
- How is adult education considered in policies and practice in Mozambique?

- Which are the main challenges for the effective adult education programmes?

\section{Problem of Research}

Adult education in developing countries, as is the case of Mozambique, is in general linked to ambitious expectations, such as poverty reduction, social inclusion and increased participation of youth and adults in social and economic spheres of society. However, studies show that in practice adult education in Mozambique tends to be seen as only literacy and numeracy skills teaching offered to out of school youth and adults (Luís, 2012). Torres (2004, p. 12) referring to developing countries, noted that literacy is perceived "as a simple elementary skill". This understanding and practice contradict the actual youth and adults' aspirations which go beyond the acquisition of basic writing, reading and calculation skills.

\section{Research Focus}

The context of rapid changes, which characterizes the today's societies increases social exclusion, poverty, unemployment, and the gap between the rich and the poor as well as social disintegration (Torres, 2004). This scenario has an influence in increasing frustration amongst people. The world is becoming standardized by the neoliberal culture brought by globalization promoting competition and individualism. Adult education has an important role in this context, not as a miraculous solution but as a mean to improve people's competences, attitudes, values and awareness for their active participation in the construction and reconstruction of their lives. This is not possible in the environment of illiteracy and ignorance. The linkage between effective youth and adult education and participation in democracy and economy is of international consensus (Luís, 2012).

In the micro level, studies showed that adults, particularly women who achieved considerable levels of education, "are likely to ensure that their children go to and remain in school" (Fien \& Hughes, 2007, p. 17). This can contribute to reduce drop outs in schools and to help many children, adolescent and youth to develop foundational skills. These skills are crucial for their continuing learning and contribute for the reduction of illiteracy amongst youth and adults in Mozambique.

Studies emphasize the benefits of investment on education as a key strategy in the fight against poverty. To implement this ideal, "new objectives, priorities and goals are established on a global scale in order to increase the level of education of the population as a whole and increase its effectiveness..." (Tarabini, 2009, p. 204).

In this agenda, amongst different instruments, the Sustainable Development Goals (SDGs) can be pointed out. The SDG 4 intends to "ensure inclusive and equitable quality education and promote lifelong learning opportunities for all". The focus of this goal is "on the acquisition of foundational and higher order skills, greater and more equitable access to technical and vocational education and training and higher education throughout life, and the knowledge, skills and values needed to function well and contribute to society" (United Nations, 2009, p. 5). This goal constitutes a challenge for many developing countries, of which Mozambique is not an exception.

The limitations that characterize adult education hamper people's opportunity to enjoy their right to education and limit the chance of improving their lives. Drawing from Freire, a Brazilian educator and philosopher widely known in education through his work entitled "Pedagogy of the oppressed", in which he discusses his ideas of critical pedagogy and his interpretations of the world, it is possible to say that the different barriers to learning in adult education are the negation of people's "ontological vocation to be more fully humans" (Freire, 2005, p. 74). 
To improve their potential, people need to learn without limits. "Learning is an essential ingredient to the growth and development of the human person..." (Jarvis, 2007, p. 125). Thus, the limiting situations in adult education can be considered as the 'distortion' of the most basic 'vocation' of youth and adults, as human beings - the vocation of becoming more fully humans. In that sense, adult education should offer empowering opportunities.

The concept of empowerment is widely linked to adult education and to Freire's philosophy, who suggested a project of liberating the oppressed people of the world through education (Hur, 2006). Recently the concept of empowerment is used in a variety of scientific fields. It is a complex social process which can take place in various dimensions of life including sociological, psychological, economic and political, as well as in various levels such as individual, group and community (Hur, 2006).

Empowerment in the learning context "is the development of knowledge, skills and abilities in the learners to enable them control and to develop their own learning" (Nwanosike, 2012, p. 216). This concept is associated to the strengthening of people's capacities resulting in an increased ability to make choices, to take decisions and to generate positive changes in their lives. It can also be interpreted as "gaining power and control over decisions and resources that determine the quality of one's life" (Nwanosike, 2012, p. 216).

Adult education, particularly in the framework of development, needs to be an empowering process. "We must consider this a process which goes beyond the simple teaching of reading and writing" (Gõni, 2006, p. 114) towards functional knowledge and competences development. In this study adult education is seen as educational activities organized to provide knowledge, skills and attitudes to people considered as adults. In the context of Mozambique adult education programmes (specially literacy classes) include adolescents and youth who by different reasons could not enroll in the regular classes in formal primary education.

To carry out this research the following methodology was used.

\section{Methodology of the Research}

\section{General Background}

This research is qualitative; it values the interpretation of data and the authors' experience to produce knowledge. It generates "words, rather than numbers, as data analysis" (Mack, Woodsong, MacQueen, Guest \& Namey, 2005, p.2). It focuses on adult education in Mozambique, and it was carried out between February and November 2017.

\section{Research Sample}

This research results from content analysis of documents. Therefore, it is based on a set of documents, namely Mozambique's policy documents on education, particularly adult education (strategic plans of education, Strategy of Literacy Adult Education and Non-Formal Education 2001-2005, Strategy of Literacy and Adult Learning, 2010-2015) and different evaluation reports and studies.

The criterion of selection was based on their credibility, they are published documents related to adult education in Mozambique, basically from the year 2001, the year of implementation of the first strategy of adult education in the country.

\section{Instrument and Procedures}

In this research, electronic and printed documents were used. According to Bowen (2009), document analysis is a systematic process for reviewing and evaluating printed and electronic material. The researchers selected the documents purposively based on their judgments oriented by the aim of the research, the research questions and their experience as researchers and lectures in adult education. 
PROBLEMS

OF EDUCATION

IN THE $21^{\text {st }}$ CENTURY Vol. 75, No. 6,2017

584

For data collection, the documents were read repeatedly, and the data were selected and transcribed to allow its analysis. Later, the selected data were interpreted; compared and the similar ones were reduced.

After data analysis the initial findings were shared with professionals on adult education who contributed to improve them. According to Brink (1993, p. 37) "to reduce threats to internal reliability with data analysis" in qualitative research, "peer examination" is required.

\section{Data Analysis}

Concerning data analysis, the research employs content analysis of documents, a "subjective interpretation of the content of text data through the systematic classification process of coding and identifying themes..." (Hsieh \& Shannon, 2005, p. 1278). The main purpose of content analysis is to generate "knowledge and understanding of the phenomena under study" (Downe-Wamboldt, 1992, p. 314). As Bowen (2009) advises, data require to be examined and interpreted in order to bring meaning and develop empirical knowledge.

The analytical process in this research was based on examination of data, selection of relevant excerpts from the texts and comparison of different excerpts. Similar data were reduced, and the excerpts were organized according to their meaning, interpreted and coded. The process of constant reading and interpretation of data led to identification of the categories that were repeatedly compared with the entire data. This process allowed the reduction of the number of categories by aggregation of similar data to the same category. According to Rossman and Rallis (2003), in qualitative research, researchers use their own experience and perception to make sense of the data and the world they explore.

The results of this research are presented in the section below.

\section{Results of the Research}

The findings of this research come from the content analysis of documents. They are aligned with the respective objectives, research questions and are based on the adopted theoretical framework, as well as the researchers' own experiences and understanding of the topic.

\section{Adult Education in Mozambique}

Adult education in Mozambique is widely administrated by the National Directorate for Literacy and Adult education, and guided by a strategic plan which is designed to be implemented in five years, but by different reasons the strategies are implemented in more than five years. For instance, the first strategy of adult education that was implemented in 2001 was extended until 2009.

The objective of the Strategy of Literacy Adult Education and Non-Formal Education for 2001 to 2005 (the first strategy in the area of Literacy and adult education in Mozambique) was to promote, coordinate and ensure equal access to basic education for youth and adults, in partnership with the civil society in order to eradicate illiteracy towards economic, social and cultural development and poverty reduction in Mozambique (Ministério da Educação e Cultura, 2001). This strategy focused on the improvement of three challenging areas. These areas are presented as part of the findings of this study to allow the discussion on what is stated in policies (aspirations) and the practices.

\section{Access to Adult Education Programmes}

The issue of access to adult education programmes, according to Ministério da Educação e Cultura (Ministry of Education and Culture) (2001), includes increased participation and 
retention of youth and adults in the training programmes with special attention to girls and women. Retention in adult education includes literacy teachers themselves, as many of them use to drop out from literacy classes.

\section{Quality Improvement}

The matter of quality included different aspects; some of them are the development of a new curriculum and the increased development of human resources. This strategy was the first one with vocational subjects.

\section{Reinforcement of Institutional Capacity}

This issue includes the continuing development and implementation of policies and strategies for the subsector of Literacy and Adult Education, as well as the improvement of resources and the increase of funding. These aspects also contribute for quality programmes, which can respond to the learners' needs, and increase their chances to participate in the social and economic spheres in their communities and society.

The curriculum was planned to include not only literacy and numeracy skills, but also other topics such as vocational skills, 'good' attitudes, civic and cultural values, including the culture of peace and democracy. Seven years later, the implementation of the first literacy, adult education and non-formal education strategy in the country was evaluated (Lind, Patel, Buque, Buduia, Cambaza \& Cambula, 2008). The main aim was to get foundations for the development of the second adult education strategic plan, which was planned to be implemented from 2010 to 2015 .

This strategy was named Strategy of Adult Literacy and Learning in Mozambique 20102015. Its purposes are to "increase learning opportunities for young people and adults in order to improve their living conditions and the communities where they live" (Ministry of Education, 2011, p. 15). "The overall goal of this Strategy is to increase opportunities for young people and adults to become literate, with special attention to women and girls in order to reduce illiteracy" (Ministry of Education, 2011, p. 23).

\section{Achievements in Adult Basic Education Programmes}

According to Lind, Patel, Buque, Buduia, Cambaza and Cambula (2008), during the implementation of the Strategy of Adult Education and Non-Formal Education 2001-2005 in Mozambique, some encouraging aspects were registered. The strategy itself represents a great progression in Adult Education, as it is the first one in this area in the country. It contributed for the increase of enrolment of youth and adults in educational programmes, as well as the establishment and strengthening of partnership between the now Ministry of Education and Human Development, with different governmental and non-governmental institutions, as well as religious organisations.

The involved organisations carried out different responsibilities. The most remarked are related to financial support. For instance, non-governmental organizations were included in the provision of funds for the subsidies of literacy teachers, and for the implementation of vocational courses - the so-called 'educação-não formal profissionalizante'- (professionalizing non-formal education) and the related activities (monitoring and evaluation) at the provincial level with collaboration of the local directorates (Lind, Patel, Buque, Buduia, Cambaza \& Cambula, 2008).

In the context of implementation of the first adult education strategy, the vocational courses were designed taking into account the needs of the learners and their communities (Van der Linden \& Manuel, 2011). In this sense organic horticulture production, small business management and low cost construction were implemented in the provinces of Inhambane, Manica and Sofala, respectively. These courses were implemented in the regular literacy classes. 
PROBLEMS

OF EDUCATION

IN THE $21^{\text {st }}$ CENTURY Vol. 75, No. 6,2017

586

It is important to mention that the strategic plan 2001-2005 (even the subsequent one) privileged three approaches of literacy in Mozambique. The already mentioned regular literacy programme; literacy via radio and the REFLECT (Regenerated Freirean Literacy Through Empowering Community Techniques) programme. While the former is the most comprehensive, as it is offered countrywide, REFLECT is the less spread and less known literacy programme in the country. According to Bhalalusesa (2003), REFLECT is based on dialogue and action, awareness-raising, collaboration and empowerment. In this methodology the learners explore common problems in their communities and try to identify ways to solve such problems. In this process some relevant topics emerge and from them teachers find ways to teach literacy and numeracy.

The existence of a variety of literacy programmes increases people chances of choices. However, regular literacy is the most preferred as it offers opportunity to continue in other levels of education and it is considered equivalent to basic formal education. This means that at the end of the level three, participants get a certificate equivalent to grade five of formal education, but the same do not occur in other types of literacy programmes, as they do not get equivalence.

The second strategy, which was planned for 2010-2015, also privileged the three approaches to literacy, to make available different choices for the potential participants and increase access to learning.

\section{Barriers to Effective Adult Education and Learning}

There are different factors that contribute for low quality and lack of relevance of literacy and adult education programmes in Mozambique. Some of these factors are related to the quantity and quality of literacy teachers. For instance, in 2008 approximately 80 percent of literacy teachers were volunteers, with low educational background and with no specific training, and then the existing number of professional literacy teachers could not respond to the demand (Ministry of Education and Culture, 2011).

The Ministry of Education (2011) noted that the motivation of literacy teachers was weak; being one of the main causes attributed to irregularities in payment of their subsidies (that are only symbolic payment). Buque (2013), in his study of literacy programmes in Pemba (located in the northern part of Mozambique) and Boane (in the Southern part), found demotivated literacy teachers as a result of irregular payment of the subsidy, which is very low (650 Meticais - around 10 American dollars per month). Accordingly, some of the literacy teachers quit and seek out other activities that can ensure better income.

Mangrasse (2004) refers that the layout of literacy and adult education programmes are excessively formal. This formalism humpers flexibility in terms of attainment of learners learning needs and implementation of learner centred learning - one of the requisites of adult education. The implementation process of the programmes does not include actions of monitory or programme evaluation to allow critical reflection and possibility for programme improvement or a permanent teacher training (Vieira, 2006).

The other factor is the lack of teaching and learning materials. Teachers do not have appropriate material, mainly in level three, wherein they use books from formal education. Due to their social and economic condition, the learners cannot provide learning material from themselves and the literacy centres cannot support them (Vieira, 2006). This aspect and the lack of relevance of the literacy programmes can be part of the factor that contributes for learners drop out. For instance, Buque (2013) noted that learners drop out from the literacy programmes, specially literacy through radio, due to disparity between their expectations and the programme content, which is very basic and limited. 


\section{Discussion}

Adult education in the context of Mozambique is seen as fundamental for the development of skills for youth and adults for their participation in the wider social life. For instance, the strategy of adult education, 2001-2005 aimed at eradicating illiteracy, towards economic, social and cultural development in Mozambique (Ministério da Educação e Cultura, 2001). However, this aspiration is less aligned to the existing condition in the field.

Literacy teachers do not have enough competences to appropriately deal with the teaching process, which impacts negatively the learning process and the objectives of adult education. Manuel, Popov and Buque (2015) concluded that adult education programmes tend to be teacher centred. This aspect on one hand contributes for lack of empowering learning experiences; on the other hand, hampers creativity and critical thinking on the learners.

The issue of lack of participation and drop outs can be, in part, attributed to these aspects, since adult learners are motivated to learn when they realize that they can apply the new knowledge to solve real problems in their lives.

The scenario in which the majority of literacy teachers are volunteers (in 2008 they were around 80 percent) (Ministry of Education, 2011) and lacking appropriate support, cannot contribute to effective and relevant adult education. Teachers use to wait around two or six months without earning their subsidies, which is just a symbolic payment. In this situation many literacy teachers drop out and try to find other activities for their subsistence in other areas of activity.

Looking at these different limitations one can question to what extent the knowledge and skills acquired in the three levels of literacy programmes can be in fact, equivalent to the knowledge and skills acquired in grade five of formal education, as stated by the Ministry of Education and Human Development in Mozambique.

According to Gõni (2006, p. 123), "adult education is oriented to prepare individuals for their civic and social responsibilities and responding to their requirements, needs and aspirations, while offering opportunities and ways to develop their personality", which requires competent and motivated literacy teachers and relevant curriculum. The investment for curricula improvement has been attempted in the context of implementation of adult education strategies. For instance, in the strategy for 2001-2005, which lasted up to 2009, the improvements were basically characterized by the introduction of vocational skill contents in literacy classes. This innovation contributed to an increased participation and retention of learners. However, it did not last longer due to lack of facilitators in vocational courses and lack of material for practice.

The negative experience, in terms of interruption of the vocational courses, contributed to a certain extent for the reduction of focus on these courses in the subsequent Strategy the Strategy of Literacy and Adult Education, 2010-2015. In this Strategy the "educação nãoformal profissionalizante" (as vocational courses were named), is not clearly mentioned as one of the objectives in literacy and adult education. The effort of programme design, development of manuals for the learners and teachers, and teacher training for vocational education was tried away. Nowadays vocational courses are not implemented in literacy classes (Van der Linden \& Manuel, 2011), and the purpose of dissemination of experiences in this matter in the whole country disappeared.

The second strategy of literacy and adult education for 2010-2015 focuses on adult education as literacy in its narrow sense as teaching of literacy and numeracy skills, and the concept of non-formal education as referring to other skills is not clearly developed. This can be also seen from its designation as "Strategy of adult literacy and learning in Mozambique 2010-2015.

Non-formal education as vocational training is not widely planned as it was in the first strategy. The focus is on literacy. Undoubtedly, literacy skills are needed as they help people to improve other competences. But literacy should be considered as foundational skills, not as the end in itself. Literacy teaching should be seen as a process which goes beyond the simple 
PROBLEMS

OF EDUCATION

IN THE $21^{\text {st }}$ CENTURY Vol. 75, No. 6,2017

588

ing of reading and writing in order to place it within the purposes of achieving functional skills, to help people to deal with and adopt social changes in their contexts (Gõni, 2006). "There is a growing international consensus that basic education that includes life skills for young people and adults provides an essential tool to encourage participation in democracy and in economy" (Luís, 2011, p. 4). This means that adult education in the context of Mozambique is still implemented in a narrow perspective. This is a great challenge specially in the context of growing social and economic changes, which contrasts with the increased economic and social inequalities in the country.

Adult education "is perceived to give the individuals the capacity to make choices in all areas of life. The choices include being able to work in dignity, supporting themselves and their families, as well as being respected and effective member of a community" (Fien \& Hughes, 2007 , p. 16). Adult education is the empowerment of youth and adults and this cannot happen without a diversity of powerful learning experiences in an appropriate context.

\section{Conclusions}

This research aimed to gain insight of adult education in the context of Mozambique, focusing on the main policies of adult education and on the main challenging factors for the effective adult education. It concludes that, apart from literacy skills development, adult education is linked to economic development, social inclusion and poverty reduction. These are the main aspirations expressed in police documents, particularly in developing countries, including Mozambique. However, Mozambique is still limited to provide sound policy framework that can offer appropriate environment for the development of quality and relevant adult education towards lifelong learning perspective.

Literacy is fundamental in Mozambique mainly when we consider that more than a half of youth and adults are not able to read and write, but it cannot be seen as a goal of adult education. Literacy and numeracy are the pillars skills that all youth and adult need to be able to benefit from other learning opportunities. If adult education aims to tackle poverty and exclusion it should be an empowering process providing a variety of quality learning opportunities in a continuing process. In this sense the providers of adult education, particularly the educational sector, need to design sound policies framework that can contribute to strengthen partnership with different actors. These actors could be a) universities, by involving students in their practical activities as mediators of adults learning, as well as their lecturers in the process of training, monitory and evaluation of the training programmes and research on literacy programmes; $b$ ) Non-Governmental Organisations, in a collaborative process and exchange of experiences. This may help adult education to increase participation of youth and adults in social, economic and political life towards achievement of its aspirations.

\section{References}

Bhalalusesa, E. (2004). Towards sustainable development through reflect methodology in Tanzania: Major trends and lessons. Adult Education and Development, 6, 51-61.

Bowen, G. (2009). Document analysis as a qualitative research method. Qualitative Research Journal, 9 (2), 27-40.

Brikci, N. \& Green, J. (2007). A guide to using qualitative research methodology. London: London School of Hygiene and Tropical Medicine. Retrieved 10/09/2017, from https://cloudfront.ualberta.ca/-/ media/science/research-and-teaching/teaching/qualitative-research-methodology.pdf.

Brink, H. (1993). Validity and reliability in qualitative research. Paper delivered at SA Society of Nurse Researchers' Workshop. Retrieved 31/01/2016 from https://www.curationis.org.za/index.php/ curations/article/.../1350.

Buque, D. (2013). Literacy Programmes in Mozambique: Adults'motivations, needs and expectations. Doctoral thesis. University of the Western Cape. 
Downe-Wamboldt, B. (1992). Content analysis: Method, applications and Issues. Health Care for Women International, 13, 313-321.

Fien, J. \& Hughes, Ph. (2007). Education and the end of poverty. Three ways forward. In M. Clarke \& S. Feeny (Eds.) Education for the end of poverty: Implementing all the Millennium Development Goals. (pp 11-21) New York: Nova Science Publishers.

Freire, P. (2005). Pedagogy of the oppressed. London: Continuum.

Gadotti, M. (2009). Educação de adultos como direito humano [Adult education as human right]. São Paulo: Editora e Livraria Instituto Paulo Freire.

Gõni, J. (2006). What is adult education? UNESCO answers. San Sebastian: UNESO Centre. Retrieved 2/6/2016, from http://www.unesdoc.unesco.org/images/0014/001494/149411e.pdf.

Hsieh, H. \& Shannon, S. (2005). Three approaches to qualitative content analysis. Qualitative Health Research, 15 (9), 1277-1288.

Hur, M. (2006). Empowerment in terms of theoretical perspectives: Exploring a typology of the process and components across disciplines. Journal of Community Psychology, 34 (5), 523-540.

Jarvis, P. (2007). Globalisation, lifelong learning and the learning society. Sociological perspective (Vol. 2). London: Routledge.

Lind, A., Patel, S., Buque, D., Buduia, I., Cambaza, A., \& Cambula, A. (2008). Análise da situação de alfabetização educação de adultos e educação não-formal em Moçambique [Situational Analysis of literacy, adult education and non-formal education in Mozambique]. Maputo: UNESCO/ Ministério da Educação e Cultura.

Luís, R. (2012). Youth and adult learning and education in Mozambique. Kwazulu-Natal: Open Society Initiative for Southern Africa (OSISA) \& Internationale Zusammenarbeit des Deutschen Volkshochshul-Verbandes (DVV International). Retrieved 28/04/2014 from http://www.osisa.org/ sites/default/files/mpzambiqueyale final.pdf.

Mack, N., Woodsong, C., MacQueen, K., Guest, G., \& Namey, E. (2005). Qualitative research methods. A data collector's field guide. North Carolina: Family Health International. Retrieved 9/11/2017 from https://www.fhi360.org/.../Qualitative\%20Research\%20Methods\%.

Mangrasse, L. (2004). A ideologização do processo de alfabetização e educação de jovens e adultos na província de Nampula, Moçambique, no periodo de 1975 a 2003: Tensão entre factores políticos e culturais [The ideologization of literacy and youth and adult education process in Nampula province, Mozambique, between 1975 and 2003: Tension between political and cultural factors]. Tese de Doutoramento. São Paulo: Pontifícia Universidade Católica.

Manuel, A., Popov, O., \& Buque, D. (2015). Towards programme improvement in non-formal vocational education and training. Problems of Education in the 21st Century, 67, 61-70.

Ministério de Educação e Cultura [Ministry of Education and Culture] (2006). Plano estratégico de educação e cultura 2006-2010/11 [Strategic plan of education and culture 2006-2010/11]. Maputo: Ministério da Educação e Cultura.

Ministério da Educação [Ministry of Education and Culture] (2001). Estratégia do subsector de Alfabetização e educação de adultos/educação não formal [Strategy of the sub-sector of literacy, adult education and non-formal education]. Maputo: Ministério de Educação.

Ministry of Education (2011). Strategy of adult education and learning in Mozambique 2010-2015. Maputo: Ministry of Education.

Nwanosike, O. (2012). Importance of capacity building, human resources development and empowerment. Nigeria Journal of Education, Health, Environment and Technology Research, 3 (1), 213-220.

Rossman, G., \& Rallis Sh. (2003). Learning in the field: An introduction to qualitative research. $2^{\text {nd }}$ ed. London: SAGE Publications.

Tarabini, A. (2009). Education and poverty in the global development agenda: Emergence, evolution and consolidation. International Journal of Educational Development, 30, 204-2012.

Torres, R. (2004). Lifelong learning in South: Critical issues and opportunities for adult education. Sisa studies no II. A. Sisak (Ed.). Stockholm: Edita Sverige AB. Retrieved 17/07/2015, from http:// www.sida.se/.../lifelong-learning-in-the-south-critical-issues-and-opportunities-for-ad.

United Nations (2016). The sustainable development goal report. New York. Retrieved 16/03/2017 from http://unstats.un.org/sdgs/report/2016/The\%20Sustainable\%20Development $\% 20$ Goals\%Report\%\%202016.pdf.

Van der Linden, J. \& Manuel, A. (2011). Beyond literacy: Non-formal education programmes for adults in Mozambique. Compare, 41 (4), 467-480.

Vieira, M. (2006). Educação de adultos, analfabetismo e pobreza em Moçambique [Adult education, illiteracy and poverty in Mozambique]. Piracicaba: Universidade Metodista de Piracicaba. 
Alzira A. M. MANUEL, Domingos BUQUE, Rosário QUIVE. Adult education in Mozambique: Between expectations and possibilities OF EDUCATION THE $21^{\text {st }}$ CENTURY Vol. 75, No. 6, 2017

\begin{tabular}{|ll|}
\hline Alzira A. M. Manuel & PhD, Lecturer, Eduardo Mondlane University, Julius Nyerere Av. P.O. Box \\
& 257, Maputo, Mozambique. \\
& E-mail: alzira@uem.mz; alziramanuel92@gmail.com \\
\hline Domingos Buque & $\begin{array}{l}\text { PhD, Lecturer, Eduardo Mondlane University, Julius Nyerere Av. P.O. Box } \\
\text { 257, Maputo, Mozambique. } \\
\text { E-mail: domingos.buque@uem.mz }\end{array}$ \\
\hline Rosario Quive & Msc. Lecturer, Eduardo Mondlane University, Julius Nyerere Av. P.O. Box \\
& 257, Maputo, Mozambique. \\
E-mail: rosquive@yahoo.com
\end{tabular}

